\title{
Delay in calling for help during myocardial infarction: reasons for the delay and subsequent pattern of accessing care
}

\author{
W S Leslie, A Urie, J Hooper, C E Morrison
}

\begin{abstract}
Objective-To determine the reasons for delay in calling for help during acute myocardial infarction and the reasons for choice of first medical contact.

Design-Review of routine medical records and one to one semi-structured interviews.

Setting-Community survey in city of Glasgow, north of the river Clyde.

Patients-228 men and 85 women aged between 25 and 65 years, respectively, who survived acute myocardial infarction between October 1994 and December 1996.

Results-Only $25 \%$ of the subjects made a call for help within one hour of the onset of coronary symptoms; in $40 \%$ the delay was greater than four hours. Symptoms were not recognised as coronary in origin in the majority of cases. In all cases where delay was more than one hour the main reasons for the delay were thinking that symptoms would go away or that they were not serious. Requesting the attendance of a general practitioner was the first course of action in the majority of cases (55\%); the main reason given was that the patient believed this should always be the first course of action. Reluctance to call the emergency services reflected the belief that the symptoms were not serious enough to warrant an ambulance.

Conclusions-Strategies to reduce patient delay times in this deprived urban population must focus on educating the public on the recognition and diversity of coronary symptoms and the benefits of presenting promptly to hospital by way of the emergency ambulance service.

(Heart 2000;84:137-141)
\end{abstract}

Keywords: myocardial infarction; treatment delay

The advent of thrombolysis has highlighted the fact that delayed hospital presentation is the greatest contributor to postponed treatment of acute myocardial infarction and a critical determinant of the initial management strategy. ${ }^{1}$ The most significant factor in delay from the onset of coronary symptoms to reaching definitive coronary care has been identified as delay in calling for medical help.

A clearer understanding of why such delays occur may help to improve public education aimed specifically at reducing patient delay and to increase ambulance use under such circumstances, the ambulance being the locally agreed first line service in Glasgow. Implementation of such strategies may help reduce out of hospital coronary mortality, which is around $66 \%$ of all mortality during acute myocardial infarction in Glasgow, ${ }^{2}$ and maximise the known benefits of thrombolytic treatment.

The aims of this study were therefore to determine the reasons why patients experiencing symptoms of acute myocardial infarction delay in calling for help, and the reasons for their subsequent course of action.

\section{Methods}

The study population consisted of 313 consecutive surviving cases from the Glasgow MONICA (monitoring trends and determinants in cardiovascular disease) coronary event register, fulfilling MONICA criteria for definite non-fatal myocardial infarction, aged between 25-64 years inclusive, and resident in the city of Glasgow, north of the river Clyde. All events occurred between October 1994 and
December 1996. The main sources of case ascertainment and criteria for definite myocardial infarction have been described previously. ${ }^{3}$

All 313 cases attended for coronary risk factor screening 3-9 months after hospital discharge as part of the ECTIM (étude cas-temoin sur l'infarctus du myocarde) study, a case-control study of acute myocardial infarction survivors carried out in the Glasgow MONICA population.

Before risk factor screening review of each subjects' hospital case notes was carried out to determine the following:

- patient demographics;

- previous medical history;

- coronary symptoms and their time of onset;

- delay between onset of symptoms and call for medical help;

- first medical contact.

Reasons for delay in calling for medical help and choice of first medical contact were ascertained at the screening session in a one to one semi-structured interview.

We used a $\chi^{2}$ test to determine the significance of the differences between the groups examined. The expected values for this test were calculated to take account of the difference in the sizes of these groups.

\section{Results}

We interviewed 228 men and 85 women. Sixty nine subjects $(22 \%)$ had a history of previous acute myocardial infarction, 58 (84\%) of whom also suffered from angina; $61(20 \%)$ had a history of angina alone and 183 (58\%) had no previous cardiac history. 
Table 1 Perception of symptoms according to past medical history

\begin{tabular}{lcccrrr}
\hline Past medical history & Angina & Indigestion & No idea & \multicolumn{1}{c}{ Other } & \multicolumn{1}{l}{ MI } & \multicolumn{1}{c}{ Total } \\
\hline MI \pm angina & $18(26)$ & $9(13)$ & $5(7)$ & $9(13)$ & $28(41)$ & $69(22)$ \\
Angina alone & $18(30)$ & $15(24)$ & $12(20)$ & $9(15)$ & $7(11)$ & $61(20)$ \\
No cardiac history & $8(4)$ & $59(32)$ & $41(22)$ & $48(26)$ & $27(15)$ & $183(58)$ \\
Total & $44(14)$ & $83(27)$ & $58(18)$ & $66(21)$ & $62(20)$ & $313(100)$ \\
\hline
\end{tabular}

Values are $\mathrm{n}(\%)$.

MI, myocardial infarction.
REASONS FOR DELAY

Reasons for delaying more than one hour before calling for medical help were similar in all cases, irrespective of sex or past medical history. The most frequently given reason was "thinking that the symptoms would go away" and "not thinking it was serious". Self treatment with nitrates was a frequent cause of delay among those with a history of acute myocardial infarction or angina (table 2).

Chest pain was experienced in most cases $(n=269(86 \%))$. In 108 cases $(35 \%)$ it was the only symptom. In 178 cases ( $57 \%)$, chest pain was accompanied by other symptoms (pain in the arm, neck, jaw, breathlessness).

\section{PERCEPTION OF SYMPTOMS}

Most subjects with a history of previous acute myocardial infarction recognised their symptoms as cardiac. Twenty six per cent attributed their symptoms to angina and $41 \%$ to another acute myocardial infarct. Thirty per cent of patients with a history of angina alone attributed their symptoms to angina, and $11 \%$ to suspected acute myocardial infarction (table 1).

The majority of subjects with no cardiac history had either no idea what had caused their symptoms or thought they had indigestion. Only $19 \%$ recognised their symptoms as cardiac. Recognition of coronary symptoms among those with no cardiac history did not appear to be influenced by sex, as a similar proportion of men and women- $20 \%$ and $17 \%$ - attributed their symptoms to a cardiac cause (data not shown).

DELAY

Only $25 \%$ of all the subjects made a call for medical help within one hour of the onset of symptoms. Comparison between the sexes showed that more of these calls were made by men $(28 \% v 15 \%$; $\mathrm{p}=0.016)$. Comparison of cases with no cardiac history and those with previous acute myocardial infarction or angina showed that previous cardiac history had no influence on the number of calls made within one hour. Forty one per cent of cases had called for medical help within two hours, and $60 \%$ within four hours.

One fifth of all cases delayed more than four hours before making a call for help. In $12 \%$ of cases the delay exceeded 24 hours.

\section{FIRST MEDICAL CONTACT}

An initial call for medical help was made to the ambulance service in only $25 \%$ of all cases. More of these calls were made by people with a previous history of acute myocardial infarction $(35 \%$ v $19 \% ; \mathrm{p}=0.008)$. The reason most often given for phoning an emergency ambulance was "knowing that calling a general practitioner would take longer".

Calling a general practitioner remained the first course of action in the majority of all cases $(55 \%)$, irrespective of previous medical history. More women than men chose their general practitioner as the first medical contact $(65 \% v$ $51 \% ; \mathrm{p}=0.028)$. The most commonly reported reason for calling a general practitioner was that "symptoms were not important enough to call an ambulance". This reason was also common among those with a previous acute myocardial infarct. Many people thought phoning their general practitioner should always be the first course of action (table 3).

In $20 \%$ of cases both the ambulance and general practitioner services were bypassed and the patient presented directly to the nearest hospital emergency department, either by a taxi or by private car. The reason most often given for doing this was that it was the "quickest way of getting to hospital".

\section{Discussion}

Early administration of a thrombolytic agent reduces infarct size and improves survival. symptoms can reduce mortality by $45 \%$, and by $23 \%$ if given within three hours. ${ }^{4}$ Recent quantification of the benefit of early thrombolysis has shown that delay in administration by 30 minutes reduces life expectancy by an average of one year. ${ }^{5}$ Administration within one hour of the onset of

Table 2 Reasons for delaying more than one hour before calling for medical help

\begin{tabular}{|c|c|c|c|c|c|c|}
\hline Reasons & $\begin{array}{l}\text { All cases } \\
(n=235)\end{array}$ & $\begin{array}{l}\text { Men } \\
(n=163)\end{array}$ & $\begin{array}{l}\text { Women } \\
(n=72)\end{array}$ & $\begin{array}{l}\text { PMH of } M I \\
(n=45)\end{array}$ & $\begin{array}{l}\text { PMH of angina } \\
\text { alone }(n=49)\end{array}$ & $\begin{array}{l}\text { No cardiac history } \\
(n=140)\end{array}$ \\
\hline Thought problem would go away & 116 & 86 & 30 & 23 & 23 & 70 \\
\hline Miscellaneous & 88 & 58 & 30 & 22 & 15 & 50 \\
\hline Didn't think it was serious & 69 & 43 & 23 & 4 & 16 & 49 \\
\hline Tried own treatment first & 63 & 41 & 22 & 11 & 23 & 29 \\
\hline Had it before, usually got better & 0 & 12 & 3 & 4 & 6 & 5 \\
\hline Didn't want to make a fuss & 15 & 8 & 7 & 0 & 4 & 11 \\
\hline At social event, waited till at home & 10 & 7 & 3 & 0 & 2 & 8 \\
\hline At work, waited till at home & 6 & 3 & 3 & 1 & 1 & 4 \\
\hline Bad experience of doctors & 4 & 3 & 1 & 1 & 2 & 1 \\
\hline Waited for 2nd lay opinion & 4 & 1 & 2 & 0 & 2 & 1 \\
\hline Waited for civilised hour & 3 & 1 & 3 & 1 & 2 & 1 \\
\hline Didn't want to disturb GP & 2 & 2 & 0 & 1 & 0 & 1 \\
\hline Fear of unknown & 2 & 1 & 1 & 0 & 1 & 1 \\
\hline $\begin{array}{l}\text { Not confident to phone as an } \\
\text { emergency }\end{array}$ & 1 & 1 & 0 & 0 & 1 & 0 \\
\hline
\end{tabular}

Columns greater than $100 \%$, as more than one reason could be given per person.

$\mathrm{GP}$, general practitioner; MI, myocardial infarction; PMH, past medical history 
Table 3 Reasons for making general practitioner (GP) first medical contact for those who called GP first

\begin{tabular}{lllll}
\hline Reasons & $\begin{array}{l}\text { All cases } \\
(n=171)\end{array}$ & $\begin{array}{l}\text { PMH of } \\
(n=30)\end{array}$ & $\begin{array}{l}\text { PMH on of } \\
\text { angina alone } \\
(n=30)\end{array}$ & $\begin{array}{l}\text { No cardiac } \\
\text { history } \\
(n=111)\end{array}$ \\
\hline Not important enough for 999 & 61 & 8 & 10 & 43 \\
Miscellaneous & 57 & 9 & 8 & 40 \\
Should always call GP first & 56 & 7 & 10 & 38 \\
Thought GP would solve problem & 39 & 5 & 7 & 27 \\
Never thought of 999 & 35 & 6 & 4 & 26 \\
Didn't want to call 999 unnecessarily & 21 & 5 & 4 & 20 \\
Always call my GP & 21 & 7 & 4 & 10 \\
Didn't know what else to do & 7 & 1 & 1 & 5 \\
Friend/relative told me to & 6 & 1 & 1 & 4 \\
Public cannot call ambulance & 4 & 0 & 2 & 2 \\
GP told me to & 1 & 0 & 1 & 0 \\
\hline
\end{tabular}

Columns greater than $100 \%$, as more than one reason could be given per person.

The prehospital delay times reported here are comparable, and in some cases better, than those reported by others, ${ }^{167}$ with two thirds of cases having arrived at hospital within four hours of the onset of symptoms. However, efforts to reduce delay times are still warranted, particularly for the $40 \%$ of cases with a prehospital delay time of more than four hours, who will not benefit maximally from thrombolysis.

RECOGNITION OF SYMPTOMS

Recognising that symptoms are cardiac in origin is a crucial factor in the delay from the onset of coronary symptoms to call for medical care. ${ }^{8}$ Most participants in this study had no previous cardiac history, failed to recognise their symptoms as coronary, and did not regard them as serious. These findings are not unique to Glasgow. ${ }^{9}$ Preconceived expectations about the nature of coronary symptoms may influence behaviour and increase patient delay time if the symptoms experienced fail to match those expectations. ${ }^{810}$

Although most individuals in this study experienced chest pain, for many the perception of acute myocardial infarction is of crushing chest pain accompanied by collapse and unconsciousness, which in fact may happen in only a minority of cases. ${ }^{78}$ The perception of acute myocardial infarction as a dramatic event needs to be dispelled, and the varying nature of the symptoms emphasised-that is, the fact that the onset may be gradual, the symptoms intermittent, and the location of pain variable.

Of greater concern is our finding that one third of cases with a history of previous acute myocardial infarction and half of those with a history of angina attributed their symptoms either to indigestion or to another non-cardiac cause. Denial is thought to be a common response to coronary symptoms, and while it is probably present in some degree in all patients experiencing an acute myocardial infarct, it may be more pronounced in those with a previous cardiac history. The relation between denial and delay is difficult to evaluate and has not been investigated thoroughly. ${ }^{11}$ Patients and family members should be told to expect denial and understand that it is a usual but inappropriate response to coronary symptoms.

It is also possible that the symptoms were dissimilar to those experienced previously, either in nature or severity. This again highlights the need for education on the varying nature of coronary symptoms and the fact that variation may occur within the same individual. This knowledge is crucial for those with a cardiac history, who are at increased risk of sudden cardiac death. ${ }^{7}$

It is established that a history of previous myocardial infarction or angina does not reduce patient delay times, ${ }^{12}$ some studies reporting a positive association between angina and increased delay. ${ }^{13}$ In the present study one third of those with a history of angina attributed their symptoms to angina and not to myocardial infarction. As in other studies, ${ }^{6}$ self treatment, usually with nitrates, and thinking the pain would resolve accounted for the delay in calling for medical help. Patients who suffer from angina need to be educated on how to distinguish the symptoms of angina from those of acute myocardial infarction. They should know that if nitrates are ineffective within a defined time then they require medical attention.

FIRST MEDICAL CONTACT

Irrespective of previous medical history, the majority of calls for medical help in response to coronary symptoms were to general practitioners, the ambulance service being called first in only one quarter of cases, a finding not unique to Glasgow. ${ }^{14}$ In this country the general practitioner service is an established and familiar route to medical care, and many participants believed that calling a general practitioner should always be their first course of action. Women tend to consult their general practitioners more often than men, ${ }^{15} 16$ and their increased familiarity with the general practitioner service may explain why they contacted their general practitioner more often than men in response to symptoms. The patients' perception of their symptoms may also influence how medical care is sought. Many, including those with previous acute myocardial infarction and angina, contacted their general practitioner as they felt symptoms were not serious enough for an ambulance.

In one quarter of cases, once the decision to seek medical attention was made self transportation was considered the quickest means of getting to hospital. While these individuals appeared to appreciate the need to get to hospital quickly, they were not able to make use of the immediate care available from ambulance crews during transportation to hospital.

The early management of acute myocardial infarction aims "to reduce mortality and morbidity by reducing the time from onset of symptoms to provision of resuscitation skills, appropriate analgesia, adequate assessment, accurate diagnosis, and, where appropriate, early thrombolytic therapy". ${ }^{17}$ In the absence of contraindications, patients with acute myocardial infarction should expect to receive thrombolytic treatment within 90 minutes of alerting the medical or paramedical services. However, the achievement of these aims must take into account local circumstances, ${ }^{17}$ and strategies for meeting these needs vary between countries, within countries, and between urban and rural areas. ${ }^{18}$

In Glasgow thrombolytic treatment is given in hospital and not, as in some rural areas in 
Scotland, by general practitioners. Early administration is therefore dependent on getting quickly to hospital. While a dual response, involving both general practitioners and ambulance crews, is considered the ideal in the early management of myocardial infarction, ${ }^{17}$ in Glasgow and other cities the involvement of a general practitioner is known to increase further prehospital delay times ${ }^{6}{ }^{19-21}$ and hence the delay to receiving thrombolysis. We advocate that the public should first call the emergency ambulance service in response to coronary symptoms, thus reducing the time to thrombolysis. If a patient calls the general practitioner, the reception staff (or out of hours emergency service staff) are advised to contact the ambulance service using " 999 " and then try to contact the general practitioner.

In Glasgow, general practitioners do not as a rule carry a defibrillator. The majority of coronary deaths occur outside hospital, ${ }^{22}$ many within one hour of the onset of symptoms, and are mainly caused by ventricular fibrillation. Survival from out of hospital cardiac arrest is significantly improved if witnessed by ambulance crews and defibrillation carried out rapidly. ${ }^{23}$ Prompt activation of the emergency ambulance service in response to coronary symptoms would facilitate early defibrillation should it be required, and may help to reduce out of hospital coronary mortality, which in Glasgow accounts for two thirds of all coronary deaths. $^{22}$

EDUCATION

In any heart health education programme, it is important that the serious nature of coronary symptoms is emphasised, along with the fact that they always warrant a call to the emergency ambulance service. However, persuading the public to contact the ambulance service in preference to their general practitioner is difficult. ${ }^{24}{ }^{25}$ Effort is required on the part of the ambulance service to promote the expertise of their crews in dealing with coronary events. This may increase public confidence in the acceptability of bypassing their general practitioner and phoning an ambulance directly.

Many cardiac rehabilitation programmes include talks from representatives from paramedical services involved in the care of cardiac patients-for example, dietitians and pharmacists. The inclusion of a representative from the ambulance service may be beneficial in emphasising the importance of the emergency services in the early management of acute myocardial infarction. The decision to phone an ambulance without delay in response to coronary symptoms needs to become as automatic as phoning the fire service to deal with a fire.

While those with a previous cardiac history should be targeted, education campaigns must be aimed at all sectors of the population. To date, the effect of media campaigns, which are usually of limited duration, on patient delay times are mixed. While some succeeded in reducing the delay to call for help, they report no success in increasing the proportion of people who call the ambulance service in the first instance. ${ }^{26}$ Long term low intensity strategies aimed at raising the awareness of the general public about the benefits that can be achieved by early coronary care may be more effective in changing attitudes. ${ }^{27}$ This long term approach should start with the young, who are more aware of campaign messages. ${ }^{26}$. While they are not at immediate risk themselves, older members of their family may be. The majority of coronary events occur at home and are witnessed by other family members, ${ }^{2}$ so educating younger family members may influence the actions of others within the family.

Nurses and other health care professionals hold positions in many and various locations throughout the community, from acute care to industry and education, and are ideally placed to implement and reinforce a continuous low intensity strategy capable of reaching all sectors of the community. Raising awareness of thrombolysis and the benefits of seeking medical attention promptly through the emergency services in response to coronary symptoms should be a priority for all health care professionals in Glasgow.

No matter how well door to needle times are improved, if prehospital delays remain significant the maximum benefits of thrombolysis and a reduction in prehospital mortality will never be achieved.

We thank Caroline Gray, Division of Medicine, University Hospital Nottingham, for the use of the questionnaire developed by herself for the Nottingham Heart Attack Register.

1 Gurwitz JH, McLaughlin TJ, Willison DJ, et al. Delayed (M) have had acute myocardial infarction. Ann Intern Med 1997;126:593-9.

2 Leslie WS, Fitzpatrick B, Morrison C, et al. Out-of-hospital cardiac arrest due to coronary heart disease: a comparison of survival before and after the introduction of defibrillators in ambulances. Heart 1996;75:195-9.

3 Tunstall-Pedoe H, Morrison C, Woodward M, et al. Sex differences in myocardial infarction and coronary deaths in the Scottish MONICA population of Glasgow 1985-91. Circulation 1996;93:1981-92.

4 Gruppo Italiano per Studio della strptochinasi nell'Infarto Miocardio (GISSI). Effectiveness of intravenous thromboMiocardio (GISSI). Effectiveness of intravenous thrombo-
lytic treatment in acute myocardial infarction. Lancet 1986; lytic treatm

5 Rawles JM. Quantification of the benefit of earlier thrombolytic therapy: five-year results of the Grampian Region Early Anistreplase Trial (GREAT). F Am Coll Cardiol 1997; 30:1181-6.

6 Heriot AG, Brecker SJ, Coltart DJ. Delay in presentation after myocardial infarction. I R Soc Med 1993;86:642-4.

7 Dracup K, McKinley SM, Moser DK. Australian patients' delay in response to heart attack symptoms. Med $\mathcal{F}$ Aust 1997;166:233-6

8 Ruston A, Clayton J, Calnan M. Patients' actions during their cardiac event: qualitative study exploring differences and modifiable factors. BMF 1998;316:1060-4.

9 Hartford M, Karlson BW, Sjolin M, et al. Symptoms, thoughts and environmental factors in suspected acute myocardial infarction. Heart Lung 1993;22:64-70.

10 Johnson JA, King KB. Influence of expectations about symptoms on delay in seeking treatment during a myocardial infarction. Am f Crit Care 1995;4:29-35.

11 Dracup K, Moser DK. Treatment-seeking behaviour among those with signs and symptoms of acute myocardial infarction. Heart Lung 1991;20:570-5.

12 Dracup K, Moser DK, Eisenberg M, et al. Causes of delay in seeking treatment for heart attack symptoms. Soc Sci Med 1995;40:379-92

13 Meischke H, Eisenberg MS, Larsen MP. Pre-hospital delay interval for patients who use emergency medical services: the effect of heart related medical conditions and demographic variables. Ann Emerg Med 1993;22:1597.

14 Rawles JM, Haites NE. Patient and general practitioner delays in acute myocardial infarction. BMF 1988; 296:882-

15 Office of Population and Census Surveys. General household survey. London: HMSO, 1991.

16 Office for National Statistics. Living in Britain: results from the 1996 General Household Survey. London: HMSO,

17 Weston CFM, Penny WJ, Julian DG, on behalf of the British Heart Foundation Working Group. Guidelines for the early management of patients with myocardial infarction. BMF 1994;308:767-71. 
18 European Society of Cardiology and The European Resuscitation Council. The pre-hospital management of acute heart attacks. Recommendations of a task force. Eur Heart F 1998;19:1140-64.

19 Wallbridge DR, Tweddel AC, Martin W, et al. The potential impact of patient self-referral on mortality in acute myocardial infarction. $Q \mathcal{f}$ Med 1992;85:901-9.

20 Gray D, Keating NA, Murdock J, et al. Impact of hospital thrombolysis policy on out-of-hospital response to suspected myocardial infarction. Lancet 1993;341:654-7.

21 Birkhead JS on behalf of the joint audit committee of the British Cardiac Society and a cardiology committee of Royal College of Physicians of London. Time delays in provision of thrombolytic treatment in six district hospitals. BMF 1992;305:445-8.

22 Fitzpatrick B, Watt GCM, Tunstall-Pedoe H. Potential impact of emergency intervention on sudden deaths from coronary heart disease in Glasgow. Br Heart $\mathcal{f}$ 1992;67: $250-4$.
23 Cobbe SM, Redmond MJ, Watson J, et al. "Heartstart Scotland"-initial experience of a national scheme for out of hospital defibrillation. BMF 1991;302:1517-20.

24 Ho MT, Eisenberg MS, Litwin PE, et al. Delay between onset of chest pain and seeking medical care: the effect of public education. Ann Emerg Med 1989;18:727-31.

25 Herlitz J, Hartford M, Blohm M, et al. Effect of a media campaign on delay times and ambulance use in suspected acute myocardial infarction. Am f Cardiol 1989;64:90-3.

26 Blohm MB, Hartford M, Karlson BW, et al. An evaluation of the results of media and educational campaigns designed to shorten the time taken by patients with acute myocardial infarction to decide to go to hospital. Heart 1996;76:430-4.

27 GISSI-Avoidable Delay Study Group. Epidemiology of avoidable delay in the care of patients with acute myocardial infarction in Italy. Arch Intern Med 1995;155: $1481-7$.

\section{IMAGES IN CARDIOLOGY}

\section{Prostaglandin $\mathrm{E}_{1}$ sensitive persistent fifth aortic arch type 2}

Three types of persistent fifth aortic arch (PFAA) have been described; one of these (type 2) is characterised by atresia or interruption of the superior, embryonic fourth aortic arch and a patent inferior fifth arch. All brachiocephalic arteries arise from a common aortic trunk.

We present a case of a female neonate with increasing tachypnoea and acidosis on the fourth day of life. The femoral arteries were not palpable. On auscultation there was a $4 / 6$ harsh systolic murmur on the left thoracic side radiating to the back. The child was intubated and prostaglandin $\mathrm{E}_{1}\left(\mathrm{PGE}_{1}\right)$ administered. Angiography showed all brachiocephalic vessels originated from a single trunk (left). At the

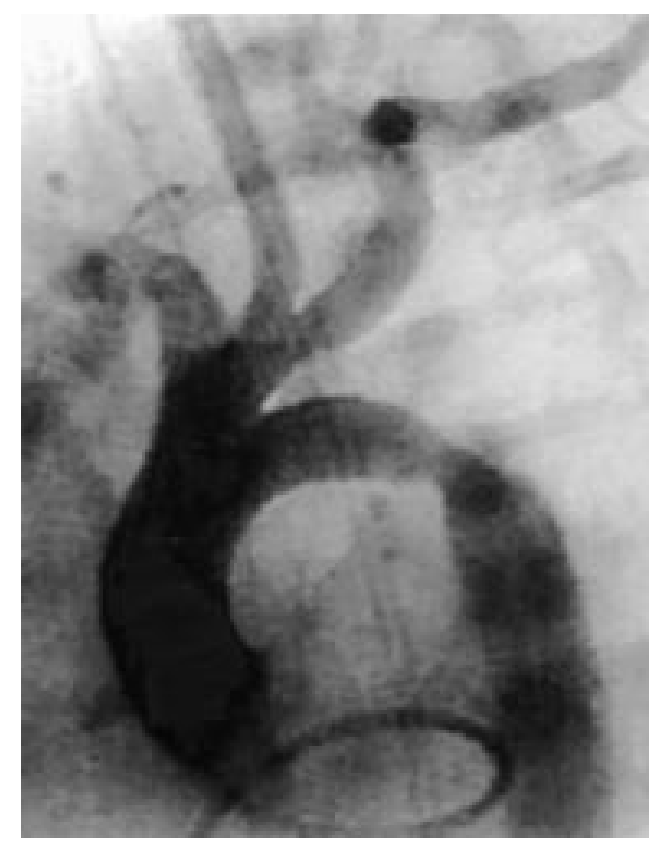

distal part of the PFAA a mild narrowing was observed. Close to the PFAA a tiny ductus arteriosus with left to right shunt was detected. When the $\mathrm{PGE}_{1}$ was stopped during cardiac catheterisation the pressure in the aorta descendens decreased from $83 / 51(64) \mathrm{mm} \mathrm{Hg}$ to $49 / 42$ (45) $\mathrm{mm} \mathrm{Hg}$ and angiography (right) showed a moderate stenosis. PGE $_{1}$ infusion was restarted. On the next day the patient underwent elective surgery. To our knowledge this is the first case describing $\mathrm{PGE}_{1}$ sensitive systemic circulation in a newborn with PFAA type 2.

P ZARTNER M B E SCHNEIDER G BEIN

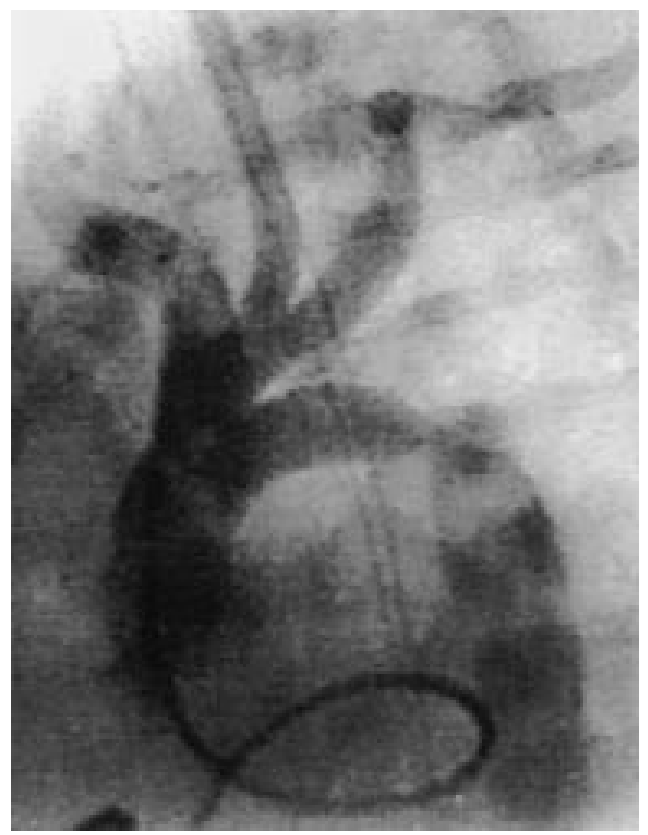

